\title{
Variation in perioperative care across centers for infants undergoing the Norwood procedure
}

\author{
Sara K. Pasquali, MD, MHS, ${ }^{\mathrm{a}}$ Richard G. Ohye, MD, ${ }^{\mathrm{b}}$ Minmin Lu, MS, ${ }^{\mathrm{c}}$ Jonathan Kaltman, MD, ${ }^{\mathrm{d}}$ \\ Christopher A. Caldarone, MD, ${ }^{\mathrm{e}}$ Christian Pizarro, $\mathrm{MD},{ }^{\mathrm{f}}$ Carolyn Dunbar-Masterson, BSN, RN, ${ }^{\mathrm{g}}$ \\ J. William Gaynor, MD, ${ }^{\mathrm{h}}$ Jeffrey P. Jacobs, MD, ${ }^{\mathrm{i}}$ Aditya K. Kaza, MD, ${ }^{\mathrm{j}}$ Jane Newburger, MD, MPH, ${ }^{\mathrm{g}}$ \\ John F. Rhodes, MD, ${ }^{\mathrm{a}}$ Mark Scheurer, MD, ${ }^{\mathrm{k}}$ Eric Silver, MD, ${ }^{1}$ Lynn A. Sleeper, $\mathrm{ScD},{ }^{\mathrm{c}}$ \\ Sarah Tabbutt, MD, PhD, ${ }^{\mathrm{m}}$ James Tweddell, MD, ${ }^{\mathrm{n}}$ Karen Uzark, $\mathrm{PhD},{ }^{\mathrm{o}}$ Winfield Wells, $\mathrm{MD},{ }^{\mathrm{p}}$ \\ William T. Mahle, MD, ${ }^{\mathrm{q}}$ and Gail D. Pearson, $\mathrm{MD}, \mathrm{ScD},{ }^{\mathrm{d}}$ for the Pediatric Heart Network Investigators
}

Objectives: In the Single Ventricle Reconstruction trial, infants undergoing the Norwood procedure were randomly allocated to undergo a right ventricle-to-pulmonary artery shunt or a modified Blalock-Taussig shunt. Apart from shunt type, subjects received the local standard of care. We evaluated variation in perioperative care during the Norwood hospitalization across 14 trial sites.

Methods: Data on preoperative, operative, and postoperative variables for 546 enrolled subjects who underwent the Norwood procedure were collected prospectively on standardized case report forms, and variation across the centers was described.

\begin{abstract}
Results: Gestational age, birth weight, and proportion with hypoplastic left heart syndrome were similar across sites. In contrast, all recorded variables related to preoperative care varied across centers, including fetal diagnosis (range, 55\%-85\%), preoperative intubation (range, 29\%-91\%), and enteral feeding. Perioperative and operative factors were also variable across sites, including median total support time (range, 74-189 minutes) and other perfusion variables, arch reconstruction technique, intraoperative medication use, and use of modified ultrafiltration (range, $48 \%-100 \%$ ). Additional variation across centers was seen in variables related to postoperative care, including proportion with an open sternum (range, 35\%-100\%), median intensive care unit stay (range, 9-44 days), type of feeding at discharge, and enrollment in a home monitoring program (range, $1 \%-100 \% ; 5$ sites did not have a program). Overall, in-hospital death or transplant occurred in 18\% (range across sites, 7\%-39\%).
\end{abstract}

Conclusions: Perioperative care during the Norwood hospitalization varies across centers. Further analysis evaluating the underlying causes and relationship of this variation to outcome is needed to inform future studies and quality improvement efforts. (J Thorac Cardiovasc Surg 2012;144:915-21)

The Norwood procedure for infants with hypoplastic left heart syndrome was first described in 1981. ${ }^{1}$ During the past 3 decades, outcomes after the Norwood procedure have improved as a result of refinements in surgical and perioperative care. ${ }^{2,3}$ Morbidity and mortality remain

From the Department of Pediatrics and Duke Clinical Research Institute, ${ }^{a}$ Duke University Medical Center, Durham, NC; the Section of Pediatric Cardiovascular Surgery, ${ }^{\mathrm{b}}$ University of Michigan, Ann Arbor, Mich; the New England Research Institutes, ${ }^{\mathrm{c}}$ Watertown, Mass; the Division of Cardiovascular Sciences, ${ }^{\mathrm{d}}$ National Heart, Lung, and Blood Institute, National Institutes of Health, Bethesda, Md; the Department of Surgery, ${ }^{\mathrm{e}}$ Toronto Hospital for Sick Children, Toronto, Ontario, Canada; the Nemours Cardiac Center, ${ }^{\mathrm{f}}$ Alfred I. duPont Hospital for Children, Wilmington, Del; the Department of Cardiology, ${ }^{g}$ Children's Hospital Boston, Boston, Mass; the Division of Cardiothoracic Surgery, ${ }^{\text {h }}$ Children's Hospital of Philadelphia, Philadelphia, Pa; the Congenital Heart Institute of Florida, ${ }^{i}$ St Petersburg, Fla; the Division of Pediatric Cardiothoracic Surgery, ${ }^{\mathrm{j}}$ Primary Children's Medical Center, Salt Lake City, Utah; the Division of Pediatric Cardiology, ${ }^{k}$ Medical University of South Carolina, Charleston, SC; the Department of Pediatrics, ${ }^{1}$ Columbia University Medical Center, New York, NY; the Department of Pediatrics ${ }^{\mathrm{m}}$ Children's Hospital of Philadelphia, Philadelphia, Pa; the Division of Cardiothoracic Surgery, ${ }^{\mathrm{n}}$ Children's Hospital of Wisconsin, Milwaukee, Wis; the Department of Pediatrics, ${ }^{\circ}$ Cincinnati Children's Hospital Medical Center, Cincinnati, Ohio; the Division of Cardiothoracic Surgery, ${ }^{\mathrm{p}}$ Children's Hospital of Los Angeles, Los Angeles, Calif; and Children's Healthcare of Atlanta, ${ }^{\mathrm{q}}$ Emory University School of Medicine, Atlanta, Ga. significant, however, and evidence to guide optimal care is still evolving. ${ }^{4,5}$

The Pediatric Heart Network, funded by the National Heart, Lung, and Blood Institute, recently conducted the Single Ventricle Reconstruction (SVR) trial, in which 555

Supported by grants HL068269, HL068270, HL068279, HL068281, HL068285, HL068288, HL068290, HL068292, and HL085057 from the National Heart, Lung, and Blood Institute. S.K.P. receives grant support from the National Heart, Lung, and Blood Institute (1K08HL103631-01) and from the American Heart Association Mid-Atlantic Affiliate Clinical Research Program. The contents of this work are solely the responsibility of the authors and do not necessarily represent the official views of the National Institutes of Health and National Heart, Lung, and Blood Institute. ClinicalTrials.gov number, NCT00115934.

Disclosures: Authors have nothing to disclose with regard to commercial support. See Appendix for a complete list of members of the Pediatric Heart Network Investigators.

Received for publication Oct 26, 2011; revisions received March 19, 2012; accepted for publication May 9, 2012; available ahead of print June 14, 2012.

Address for reprints: Sara K. Pasquali, MD, MHS, Division of Cardiology, Department of Pediatrics, Duke University Medical Center, Duke Clinical Research Institute, PO Box 17969, Durham, NC 27715 (E-mail: sara.pasquali@ duke.edu).

$0022-5223 / \$ 36.00$

Copyright (c) 2012 by The American Association for Thoracic Surgery

doi:10.1016/j.jtcvs.2012.05.021 


\section{Abbreviations and Acronyms \\ DHCA $=$ deep hypothermic cardiac arrest \\ ICU = intensive care unit \\ IQR = interquartile range \\ $\mathrm{RCP}=$ regional cerebral perfusion \\ SVR = Single Ventricle Reconstruction [trial]}

infants undergoing the Norwood procedure for hypoplastic left heart syndrome or related single right ventricle anomalies were randomly allocated to receive the right ventricleto-pulmonary artery shunt or modified Blalock-Taussig shunt as the source of pulmonary blood flow. ${ }^{5}$ The primary end point, transplant-free survival 12 months after randomization, was significantly higher in the right ventricle-to-pulmonary artery shunt group than in the modified Blalock-Taussig shunt group $(74 \%$ vs $64 \% ; P=.01){ }^{5}$ Follow-up of the trial cohort continues, to evaluate whether this survival benefit is maintained. ${ }^{5}$

Apart from shunt type, subjects enrolled in the SVR trial received local standard of care, and detailed preoperative, operative, and postoperative information was prospectively collected. Evaluation of these data provides a unique opportunity to describe the range of care across centers and to assess variation in a large, well-characterized cohort. This is an important first step in identification of areas of potential future research focus and quality improvement. Previous studies have suggested variation in several aspects of care for patients undergoing the Norwood procedure, but they have been limited in scope and by the use of retrospective survey methodology. ${ }^{4,6,7}$ The purposes of this analysis were to describe the range of perioperative care during the Norwood hospitalization across sites participating in the SVR trial and to quantitate the degree of interinstitutional variation.

\section{MATERIALS AND METHODS}

\section{Patient Population and Trial Design}

Details of the SVR trial design (ClinicalTrials.gov number NCT00115934) have been published previously. ${ }^{8}$ In brief, infants with a diagnosis of single, morphological right ventricle undergoing the Norwood procedure were eligible for inclusion in the trial. Exclusion criteria included single morphological left ventricle, preoperative anatomic features rendering either a modified Blalock-Taussig shunt or a right ventricle-to-pulmonary artery shunt technically impossible, and any major congenital or acquired extracardiac abnormality thought to independently affect survival or need for cardiac transplantation. Patients were randomized during 2005 through 2008 at 15 North American clinical centers with 39 surgeons participating. Dynamic allocation within surgeon was used to ensure that no single surgeon had a preponderance of either shunt type. All of the sites were medium- or high-volume congenital heart surgery sites. For the purposes of this analysis, a site that enrolled only 3 patients during the trial was excluded. In the remaining 14 sites, the number of patients enrolled per site ranged from 10 to 101 (median, 34). The SVR trial was approved by the institutional review boards at all participating institutions, and informed consent was obtained from a parent or guardian for each subject.

\section{Data Collection}

Detailed information regarding preoperative, perioperative, operative, and postoperative care was prospectively recorded on standardized case report forms. ${ }^{8}$ Apart from the shunt type assigned in the trial, subjects received standard care at their institutions. The postoperative period was defined as ending at the Norwood hospitalization discharge, or at the stage II procedure if the patient was not discharged between the operations. The goal of our study was to describe the range of care across sites in a large, well-characterized cohort, rather than to determine the specific underlying causes of any variation identified, so all data related to perioperative care were included. Some of the variables examined likely primarily reflect management practices, whereas others may be related more to patient characteristics or outcome. Several variables may represent a combination of these factors.

Preoperative variables collected included fetal diagnosis, fetal intervention, endotracheal intubation, use of inhaled gases, and enteral feeding. Perioperative and operative variables included age at surgery, total support time and perfusion techniques, type of aortic arch reconstruction (classic method with an allograft or xenograft patch to create the neoaorta vs direct anastomosis of the pulmonary artery to the arch), use of standard or modified ultrafiltration, and the use of various medications in the operating room (aprotinin, corticosteroids, and $\alpha$-blockade with phenoxybenzamine or phentolamine). Perfusion type was defined as either deep hypothermic cardiac arrest (DHCA), regional cerebral perfusion (RCP), or a combination of the techniques. Periods as long as 10 minutes of DHCA were included in the RCP group to allow for cannula repositioning. Lowest temperature during bypass was recorded from a core measurement site (nasopharynx, rectum, or bladder). The lowest hematocrit was recorded during bypass before initiation of DHCA or RCP.

Postoperative variables included duration of ventilation and hospital stay, whether the patient had an open sternum, postoperative interventions, including interventional cardiac catheterization, cardiac surgery, and extracorporeal membrane oxygenation (initiated either in the operating room or later in the postoperative period), in-hospital death or transplant, type and route of feeding at discharge, discharge medications, discharge on oxygen, and enrollment in a home monitoring program (including monitoring of weight gain, oxygen saturation, or both).

\section{Analysis}

Study variables were described with standard summary statistics. Aggregate rates for dichotomous variables and mean $\pm \mathrm{SD}$, median, and interquartile range (IQR) for continuous variables were calculated for the overall study population. Next, the total number of centers that used a particular practice or type of care was calculated. For these centers, centerlevel descriptive data were calculated. For continuous variables, the median value at each site was calculated; for dichotomous variables, the proportion of cases at each center in which the practice or type of care was used was calculated. Median, IQR, and range were then calculated from these centerlevel data. Because of the descriptive nature of the analysis, formal statistical comparisons were not made. All analyses were performed with the SAS version 9.2 statistical software package (SAS Institute, Inc, Cary, NC).

\section{RESULTS \\ Study Population}

Of 555 patients enrolled in the SVR trial, 5 patients had consent given but did not undergo the Norwood procedure, and 1 patient was withdrawn immediately after the Norwood procedure was performed such that no further follow-up information was collected. In addition, a site that enrolled only 3 patients was excluded. Thus the 546 remaining patients from 14 trial sites are the basis for analysis. Median birth 
weight was $3.1 \mathrm{~kg}$ (IQR, 2.8-3.5 kg), median gestational age was 38 weeks (IQR, 37-39 weeks), and 86\% had a diagnosis of hypoplastic left heart syndrome (vs other single right ventricle defects). Of note, there were no significant differences in any of these variables across sites.

\section{Preoperative Variables}

Preoperative variables are displayed in Table 1. Most patients $(76 \%)$ had their condition diagnosed in utero; however, this varied across centers, ranging from $55 \%$ to $85 \%$. Approximately half of patients were intubated preoperatively, with a range of $29 \%$ to $91 \%$ of patients across centers. Five percent overall were specifically intubated for transport (range, $1 \%-15 \%$ across 11 sites).

A minority of patients received all other preoperative therapies and interventions noted in Table 1, including fetal intervention, use of inhaled gases, and enteral feeding. Although used in a minority of patients overall, these factors also varied across sites, with the greatest variation seen in enteral feeding.

\section{Perioperative and Operative Variables}

Perioperative and operative variables are displayed in Table 2. The median age at surgery ranged from 4 to 7 days across sites. Among those who were preterm $(<37$ weeks' gestation; $\mathrm{n}=64)$, median age at surgery ranged from 2 to 23 days across centers. Total support and crossclamp times varied more than 2 -fold. There was also variation in the use of DHCA and RCP across sites, along with the lowest core temperature on bypass and lowest hematocrit (Table 2). Arch reconstruction was accomplished by the classic method in most cases. Direct anastomosis of the pulmonary artery to the arch was used in a minority of patients at 9 sites and in the majority of patients at 1 site. Ultrafiltration of any type was used at all sites; at 13 sites, it was used in most cases. Modified ultrafiltration was used at 10 sites. Perioperative steroids were used at all sites; they were administered to $100 \%$ of patients at 7 sites and to most patients at all but 1 site. Aprotinin was also used at all sites (while still available) and was used in most cases at all but 1 site. There was more variability in the use of $\alpha$-blockade, with
6 sites not using it at all and the remaining sites using it in $2 \%$ to $100 \%$ of cases.

\section{Postoperative Variables}

Postoperative variables are displayed in in Table 3. There was a 4-fold difference in duration of ventilation across sites and a nearly 5-fold variation in intensive care unit (ICU) stay. Twenty-two patients $(4 \%)$ overall were kept in the hospital until their stage II surgery, with a range of $1 \%$ to $22 \%$ of patients across 8 sites. More than three-quarters of patients had an open sternum after the Norwood operation; this also varied across sites, ranging from $35 \%$ to $100 \%$. At 7 sites, all patients had an open sternum. Extracorporeal membrane oxygenation use ranged from $7 \%$ to $35 \%$ across sites. Interventional cardiac catheterizations and cardiac surgery in the postoperative period before discharge were infrequent but variable by site, ranging from $6 \%$ to $20 \%$ and $3 \%$ to $40 \%$, respectively. Five centers did not perform any interventional catheterizations, and 3 centers did not perform any cardiac surgeries in the postoperative period after the Norwood procedure. Overall, 18\% of patients died or underwent transplant during the primary hospitalization, with a range of $7 \%$ to $39 \%$ across sites (Table 3).

All surviving patients were discharged with at least 1 medication. The most frequent discharge medications included aspirin $(87 \%)$, furosemide $(85 \%)$, ranitidine $(50 \%)$, metoclopramide $(38 \%)$, and digoxin $(36 \%)$. The type and route of feeding were highly variable across sites. Only a third of patients overall were feeding by mouth without any nasogastric or gastric feeds at discharge, and fewer than half were receiving breast milk (alone or in combination with formula). A minority of patients $(11 \%)$ were discharged home with supplemental oxygen, but this varied by site from $2 \%$ to $57 \%$. A third of discharged patients were enrolled in a home monitoring program; 5 sites did not have such a program.

\section{DISCUSSION}

This analysis describes the wide range of perioperative care across clinical centers for patients undergoing the

TABLE 1. Variation in preoperative variables

\begin{tabular}{|c|c|c|c|c|c|}
\hline \multirow[b]{2}{*}{ Variable } & \multirow[b]{2}{*}{ Aggregate rate } & \multicolumn{4}{|c|}{ Center-level data } \\
\hline & & No. of centers & Median & Interquartile range & Range \\
\hline Fetal diagnosis & $76 \%$ & 14 & $73 \%$ & $71 \%-82 \%$ & $55 \%-85 \%$ \\
\hline Fetal intervention* & $3 \%$ & 5 & $3 \%$ & $2 \%-4 \%$ & $1 \%-17 \%$ \\
\hline Intubation & $48 \%$ & 14 & $50 \%$ & $38 \%-64 \%$ & $29 \%-91 \%$ \\
\hline \multicolumn{6}{|l|}{ Inhaled gases } \\
\hline Carbon dioxide & $3 \%$ & 5 & $16 \%$ & $1 \%-20 \%$ & $1 \%-40 \%$ \\
\hline Nitrogen & $13 \%$ & 9 & $15 \%$ & $9 \%-36 \%$ & $1 \%-55 \%$ \\
\hline Enteral feeding & $12 \%$ & 13 & $11 \%$ & $4 \%-22 \%$ & $1 \%-100 \%$ \\
\hline
\end{tabular}

Number of centers refers to the number out of the 14 total centers that used a particular practice or type of care. Subsequent center-level descriptive data in the table refer to only these centers. *Includes both patients who underwent fetal intervention at their center and those referred to another institution to undergo fetal intervention. 
TABLE 2. Variation in operative and perioperative variables

\begin{tabular}{|c|c|c|c|c|c|c|c|}
\hline \multirow[b]{2}{*}{ Variable } & \multicolumn{3}{|c|}{ Aggregate data } & \multicolumn{4}{|c|}{ Center-level data } \\
\hline & Rate & Mean \pm SD & Median (IQR) & No. of centers & Median & IQR & Range \\
\hline Age at Norwood (d) & - & $5.8 \pm 4.1$ & $5(3-7)$ & 14 & 5 & $4-6$ & $4-7$ \\
\hline \multicolumn{8}{|l|}{ Perfusion data } \\
\hline Total support time (min) & - & $144 \pm 54$ & $139(105-171)$ & 14 & 149 & $124-166$ & $74-189$ \\
\hline Crossclamp time (min) & - & $56 \pm 23$ & $53(40-67)$ & 14 & 57 & $48-64$ & $33-73$ \\
\hline DHCA only & $54 \%$ & - & - & 9 & $97 \%$ & $22 \%-100 \%$ & $3 \%-100 \%$ \\
\hline DHCA time (min) & - & $47 \pm 18$ & $42(36-54)$ & 9 & 51 & $46-55$ & $33-73$ \\
\hline $\mathrm{RCP}$ only & $24 \%$ & - & - & 10 & $38 \%$ & $19 \%-82 \%$ & $3 \%-93 \%$ \\
\hline RCP time (min) & - & $57 \pm 17$ & $55(46-66)$ & 10 & 52 & $45 \%-59$ & $30 \%-76$ \\
\hline $\begin{array}{l}\text { RCP flow } \\
\qquad(\mathrm{mL} / \mathrm{kg} / \mathrm{min})\end{array}$ & - & $42 \pm 17$ & $38(30-50)$ & 10 & 36 & $30-49$ & 19-50 \\
\hline Both DHCA and RCP & $22 \%$ & - & - & 9 & $42 \%$ & $18 \%-60 \%$ & $4 \%-87 \%$ \\
\hline DHCA time (min) & - & $25 \pm 16$ & $21(13-34)$ & 9 & 24 & $15-34$ & $12-71$ \\
\hline RCP time (min) & - & $46 \pm 22$ & $50(26-61)$ & 9 & 48 & $37-60$ & $23-71$ \\
\hline $\begin{array}{l}\text { RCP flow } \\
\quad(\mathrm{mL} / \mathrm{kg} / \mathrm{min})\end{array}$ & - & $37 \pm 16$ & $35(25-49)$ & 9 & 30 & $30-40$ & $19-54$ \\
\hline Lowest temperature $\left({ }^{\circ} \mathrm{C}\right)$ & - & $17 \pm 2$ & $17(16-18)$ & 14 & 17 & $17-18$ & $15-21$ \\
\hline Lowest hematocrit (\%) & - & $30 \pm 5$ & $29(27-32)$ & 14 & 29 & $28-31$ & $22-41$ \\
\hline \multicolumn{8}{|l|}{ Arch reconstruction } \\
\hline Classic & $88 \%$ & - & - & 14 & $97 \%$ & $82 \%-100 \%$ & $41 \%-100 \%$ \\
\hline Direct PA to arch & $12 \%$ & - & - & 9 & $15 \%$ & $4 \%-22 \%$ & $3 \%-59 \%$ \\
\hline \multicolumn{8}{|l|}{ Ultrafiltration } \\
\hline Any & $84 \%$ & - & - & 14 & $94 \%$ & $88 \%-100 \%$ & $2 \%-100 \%$ \\
\hline Modified & $66 \%$ & - & - & 10 & $94 \%$ & $88 \%-100 \%$ & $48 \%-100 \%$ \\
\hline \multicolumn{8}{|l|}{ Medications } \\
\hline Aprotinin & $78 \%$ & - & - & 14 & $87 \%$ & $60 \%-93 \%$ & $43 \%-100 \%$ \\
\hline Corticosteroids & $91 \%$ & - & - & 14 & $99 \%$ & $96 \%-100 \%$ & $33 \%-100 \%$ \\
\hline$\alpha$-Blockade & $45 \%$ & - & - & 8 & $90 \%$ & $64 \%-97 \%$ & $2 \%-100 \%$ \\
\hline
\end{tabular}

Number of centers refers to the number out of the 14 total centers that used a particular practice or type of care. Subsequent center-level descriptive data in the table refer to only these centers. $D H C A$, Deep hypothermic circulatory arrest; $I Q R$, interquartile range; $P A$, pulmonary artery; $R C P$, regional cerebral perfusion; $S D$, standard deviation.

Norwood procedure. Virtually every aspect of preoperative, operative, and postoperative care evaluated in this analysis varied across 14 sites participating in the SVR trial. Variation can foster scientific discovery and innovation and allow treatment plans to be individually tailored to the patient. Nevertheless, the degree of variability demonstrated in our analysis and others may also highlight the limited evidence to guide optimal care in this population and the lack of best practice guidelines. ${ }^{9}$ This in turn may play a role in the wide variability in outcomes after the Norwood operation. A recent analysis of more than 2000 infants undergoing the Norwood operation across 69 centers showed that adjusted in-hospital mortality varied by 6 -fold from $7 \%$ to $42 \%$ across centers. ${ }^{10}$ Data from our study, although from a smaller subset of hospitals, are similar, with the rate of in-hospital death or transplant varying from $7 \%$ to $39 \%$ across institutions. It has also been shown that variation in practice can account for a significant proportion of health care expenditures, which is of particular importance in this era of rising health care costs. ${ }^{11}$

This analysis builds on previous surveys of differences in practice across centers for patients undergoing the Norwood operation. In 2007, Wernovsky and colleagues ${ }^{6}$ surveyed 52 international centers performing the Norwood operation and reported wide variation in ICU models of care, operative and perfusion techniques, medications, feeding regimens, and postoperative monitoring. ${ }^{6}$ Other surveys evaluating not only patients undergoing Norwood operations but others undergoing congenital heart surgery have found wide variation in perfusion techniques and postoperative care models, including ICU structure and personnel. ${ }^{4,12}$ More recent studies have also analyzed specific practices in the Norwood population. Johnson and associates ${ }^{7}$ evaluated 1283 infants undergoing the Norwood procedure from 45 centers in the Society of Thoracic Surgeons Congenital Heart Surgery Database and showed that use of delayed sternal closure varied widely across centers. Other studies have evaluated a wider range of practices in patients undergoing the Norwood operation but have been limited by analyzing only survivors to hospital discharge. ${ }^{13,14}$ This study builds on these previous analyses through using prospectively collected data related to perioperative care, as opposed to retrospective survey methodology, and evaluating a wide range of care 
TABLE 3. Variation in postoperative variables

\begin{tabular}{|c|c|c|c|c|c|c|c|}
\hline \multirow[b]{2}{*}{ Variable } & \multicolumn{3}{|c|}{ Aggregate data } & \multicolumn{4}{|c|}{ Center-level data } \\
\hline & Rate & Mean \pm SD & Median (IQR) & No. of centers & Median & IQR & Range \\
\hline Total ICU stay (d) & - & $24 \pm 31$ & $14(9-25)$ & 14 & 13 & $12-18$ & $9-44$ \\
\hline Total hospital stay (d) & - & $35 \pm 34$ & $24(17-40)$ & 14 & 25 & $22-32$ & $19-44$ \\
\hline Ratio of ICU to total stay & - & $0.7 \pm 0.3$ & $0.6(0.5-1.0)$ & 14 & 0.6 & $0.5-0.6$ & $0.5-1.0$ \\
\hline Ventilator time $(\mathrm{d})$ & - & $12 \pm 25$ & $7(5-11)$ & 14 & 7 & $6-9$ & 4-16 \\
\hline Extubation within $72 \mathrm{~h}(\%)$ & $18 \%$ & - & - & 6 & $24 \%$ & $6 \%-32 \%$ & $5 \%-63 \%$ \\
\hline Open sternum $(\%)$ & $78 \%$ & - & - & 14 & $99 \%$ & $67 \%-100 \%$ & $35 \%-100 \%$ \\
\hline ECMO $(\%)$ & $16 \%$ & - & - & 13 & $18 \%$ & $13 \%-20 \%$ & $7 \%-35 \%$ \\
\hline Interventional catheterization $(\%)$ & $7 \%$ & - & - & 9 & $8 \%$ & $6 \%-11 \%$ & $6 \%-20 \%$ \\
\hline Cardiac surgery $(\%)$ & $8 \%$ & - & - & 11 & $8 \%$ & $4 \%-13 \%$ & $3 \%-40 \%$ \\
\hline \multicolumn{8}{|l|}{ Feeding at discharge } \\
\hline Oral only $(\%)$ & $33 \%$ & - & - & 12 & $29 \%$ & $18 \%-44 \%$ & $3 \%-81 \%$ \\
\hline Any oral $(\%)$ & $78 \%$ & - & - & 14 & $79 \%$ & $56 \%-90 \%$ & $33 \%-100 \%$ \\
\hline Any G/GJ tube $(\%)$ & $18 \%$ & - & - & 12 & $20 \%$ & $13 \%-27 \%$ & $2 \%-72 \%$ \\
\hline Any NG/NJ tube $(\%)$ & $49 \%$ & - & - & 11 & $60 \%$ & $53 \%-78 \%$ & $8 \%-100 \%$ \\
\hline Breast milk (any route, \%) & $48 \%$ & - & - & 14 & $47 \%$ & $39 \%-57 \%$ & $17 \%-67 \%$ \\
\hline No. of discharge medications & - & $5 \pm 2$ & $5(4-6)$ & 14 & 5 & 4-6 & $3-6$ \\
\hline Discharge with oxygen support & $11 \%$ & - & - & 11 & $11 \%$ & $5 \%-24 \%$ & $2 \%-57 \%$ \\
\hline Home monitoring program & $33 \%$ & - & - & 9 & $69 \%$ & $50 \%-96 \%$ & $1 \%-100 \%$ \\
\hline $\begin{array}{l}\text { Death or transplant during Norwood } \\
\text { hospitalization }(\%)\end{array}$ & $18 \%$ & - & - & 14 & $17 \%$ & $15 \%-30 \%$ & $7 \%-39 \%$ \\
\hline
\end{tabular}

encompassing the entire Norwood hospitalization for all patients enrolled in the SVR trial.

In the field of adult cardiac surgery, it has been shown that evaluation of variation in care across centers is a critical first step toward identifying areas of future research, development of quality improvement initiatives, and subsequent implementation of best practice guidelines. Prager and colleagues ${ }^{15}$ recently reported on The Michigan Society of Thoracic and Cardiovascular Surgeons quality collaborative. This group, composed of all adult cardiac surgery programs in Michigan, meets regularly to evaluate variation in practice and program outcomes. Through the adoption of practices used by high-performing sites, variation in care is reduced, outcomes are improved, and hospital costs are lowered. For example, after sharing of protocols to facilitate timely extubation, variation in duration of ventilation across sites was reduced, and the overall rate of prolonged ventilation decreased from $19 \%$ to $14 \% .{ }^{15}$ The Northern New England Cardiovascular Disease Study Group pioneered work in this area in adult cardiac surgery in the 1980s, and their experience has also shown that a precise assessment of variation in practice and outcomes across institutions is a critical first step. ${ }^{16}$ In pediatric cardiology, the Joint Council on Congenital Heart Disease National Pediatric Cardiology Quality Improvement Collaborative has recently begun evaluating practice variation across sites with regard to feeding and home monitoring practices in the interstage period between the Norwood and stage II procedures. ${ }^{17}$ These analyses are ongoing. Efforts are currently underway to develop a quality improvement collaborative in pediatric heart surgery.

Few previous studies have evaluated the impact on outcome of variation in management during the Norwood hospitalization. In their analysis of variation in the use of delayed sternal closure after the Norwood procedure, Johnson and associates ${ }^{7}$ found that centers with greater use of delayed sternal closure had significantly higher rates of postoperative infection and prolonged stay, differences that persisted after accounting for a variety of patient and center factors. Variation in the use of perioperative corticosteroids and its impact on outcome have also been previously evaluated. In a large study of more than 45,000 patients from 38 centers, perioperative corticosteroid use was found to vary widely by center, and in subgroup analysis, there was no significant benefit associated with corticosteroids in the high-risk group primarily composed of patients undergoing the Norwood procedure. ${ }^{18}$ Finally, investigators have also evaluated variation in center-related variables and impact on outcome. Analyses of both clinical and administrative datasets have found variation in ICU models of care (dedicated cardiac ICU vs general pediatric ICU) but have shown no significant impact of ICU type on outcome in patients undergoing the Norwood operation. ${ }^{19,20}$ Further evaluation of these and other variables examined in 
this study will help to determine which aspects of variation in care are reflective of local practices or underlying patient characteristics and are not independently associated with outcome and which are associated with improved outcomes and should be evaluated as best practices. Rather than through a single study or trial, this may best be accomplished through a collaborative effort focused on sharing of information across sites and continuous quality improvement to identify best practices, reduce variation in care, and improve outcomes, similar to initiatives in adult cardiac surgery. ${ }^{15,16}$

\section{Limitations}

There are several limitations to this analysis. This study focused on a subset of medium- and high-volume centers performing the Norwood procedure, and only patients enrolled in the SVR trial were included. We thus may have actually underestimated the degree of variation in care across all patients and across all sites performing this operation. In this initial analysis, we focused on describing the range of care across centers in a large cohort and did not evaluate the potential role of variation in care within centers, random variation between centers, or change over time. These factors will require further study. We were inherently limited to evaluating aspects of perioperative care recorded in the SVR trial data set. There may be other patient and centerlevel variables that are relevant. As noted previously, the relationship of the variation identified in this study with outcome will also require further study. Finally, in this analysis we have not separated out variation in care specifically related to practice or management from the patient's severity of disease, although we did find that the baseline patient characteristics we examined did not differ across sites. It is likely that for several of the variables we evaluated, many factors may play a role and require further analysis.

\section{CONCLUSIONS}

We have described the wide range of perioperative care across clinical centers performing the Norwood procedure. Further analysis is necessary to evaluate the underlying causes of this variation and relationship of variation in management to patient outcomes, including survival, neurodevelopmental outcomes, and cost. These analyses may aid in planning future clinical trials, allow us to begin to identify best practices, and facilitate the development of quality improvement initiatives to improve quality of care and outcomes across centers for patients undergoing the Norwood procedure.

\section{References}

1. Norwood WI, Lang P, Casteneda AR, Campbell DN. Experience with operations for hypoplastic left heart syndrome. J Thorac Cardiovasc Surg. 1981;82:511-9.

2. Pigula FA, Vida V, del Nido P, Bacha E. Contemporary results and current strategies in the management of hypoplastic left heart syndrome. Semin Thorac Cardiovasc Surg. 2007;19:238-44.

3. Graham EM, Bradley SM, Atz AM. Perioperative management of hypoplastic left heart syndrome. Expert Opin Pharmacother. 2005;6:687-93.

4. Ohye RG, Goldberg CS, Donohue J, et al. The quest to optimize neurodevelopmental outcomes in neonatal arch reconstruction: the perfusion techniques we use and why we believe in them. J Thorac Cardiovasc Surg. 2009;137:803-6.

5. Ohye RG, Sleeper LA, Mahony L, Newburger JW, Pearson GD, Lu M, et al. Comparison of shunt types in the Norwood procedure for single-ventricle lesions. N Engl J Med. 2010;362:1980-92.

6. Wernovsky G, Ghanayem N, Ohye RG, Bacha EA, Jacobs JP, Gaynor JW, et al. Hypoplastic left heart syndrome: consensus and controversies in 2007. Cardiol Young. 2007;17(Suppl 2):75-86.

7. Johnson JN, Jaggers J, Li S, O'Brien SM, Li JS, Jacobs JP, et al. Center variation and outcomes associated with delayed sternal closure after stage I palliation for hypoplastic left heart syndrome. J Thorac Cardiovasc Surg. 2010;139:1205-10.

8. Ohye RG, Gaynor JW, Ghanayem NS, Goldberg CS, Laussen PC, Frommelt PC, et al. Design and rationale of a randomized trial comparing the Blalock-Taussig and right ventricle-pulmonary artery shunts in the Norwood procedure. J Thorac Cardiovasc Surg. 2008;136:968-75.

9. Darst JR, Newburger JW, Resch S, Rathod RH, Lock JE. Deciding without data. Congenit Heart Dis. 2010;5:339-42.

10. Jacobs JP, O'Brien SM, Pasquali SK, Jacobs ML, Lacour-Gayet FG, Tchervenkov CI, et al. Variation in outcomes for benchmark operations: an analysis of the STS Congenital Heart Surgery Database. Ann Thorac Surg. 2011;92: 2184-92.

11. Fisher ES, Bynum JP, Skinner JS. Slowing the growth of health care costs-lessons from regional variation. N Engl J Med. 2009;360:849-52.

12. Burstein D, Rossi A, Jacobs J, Checchia PA, Wernovsky G, Li JS, et al. Variation in models of care delivery for children undergoing congenital heart surgery in the United States. World J Pediatr Congenit Heart Surg. 2010;1:8-14.

13. Brown DW, Conner JA, Pigula FA, Usmani K, Klitzner TS, Beekman RH 3rd, et al. Variation in preoperative and intraoperative care for first-stage palliation of single-ventricle heart disease: a report from the Joint Council on Congenital Heart Disease National Quality Improvement Collaborative. Congenit Heart Dis. 2011;6:108-15.

14. Baker-Smith CM, Neish SR, Klitzner TS, Beekman RH 3rd, Kugler JD, Martin GR, et al. Variation in postoperative care following stage I palliation for single-ventricle patients: a report from the Joint Council on Congenital Heart Disease National Quality Improvement Collaborative. Congenit Heart Dis. 2011; 6:116-27.

15. Prager RL, Armenti FR, Bassett JS, et al. Cardiac surgeons and the quality movement: the Michigan experience. Semin Thorac Cardiovasc Surg. 2009;21:20-7.

16. Likosky DS. Lessons learned from the Northern New England Cardiovascular Disease Study Group. Progress in Pediatric Cardiology. 2012;33:53-6.

17. Schidlow DN, Anderson JB, Klitzner TS, Beekman RH 3rd, Jenkins KJ, Kugler JD, et al. Variation in interstage outpatient care after the Norwood procedure: A report from the Joint Council on Congenital Heart Disease National Quality Improvement Collaborative. Congenit Heart Dis. 2011;6:98-107.

18. Pasquali SK, Hall M, Li JS, Peterson ED, Jaggers J, Lodge AJ, et al. Corticosteroids and outcome in children undergoing congenital heart surgery: analysis of the Pediatric Health Information Systems Database. Circulation. 2010;122: 2123-30.

19. Burstein DS, Jacobs JP, Li JS, Sheng S, O'Brien SM, Rossi AF, et al. Care models in congenital heart surgery and associated outcomes. Pediatrics. 2011;127: e1482-9.

20. Scheurer M, Gauvreau K, Laussen PC, Mayer JE Jr, Atz AM, Newburger JW. The impact of a designated cardiac intensive care unit on outcomes after the Norwood procedure [abstract]. J Am Coll Cardiol. 2011;57:E405. 


\section{APPENDIX. Pediatric Heart Network Investigators}

National Heart, Lung, and Blood Institute

Gail Pearson, Victoria Pemberton, Rae-Ellen Kavey*, Mario Stylianou, Marsha Mathis.*

Network Chair

University of Texas Southwestern Medical Center, Lynn Mahony.

Data coordinating center

New England Research Institutes, Lynn Sleeper (PI), Sharon Tennstedt (PI), Steven Colan, Lisa Virzi,* Patty Connell,* Victoria Muratov, Lisa Wruck,* Minmin Lu, Dianne Gallagher, Anne Devine, ${ }^{*}$ Julie Schonbeck, Thomas Travison,* David F. Teitel.

Core clinical site investigators

Children's Hospital Boston, Jane W. Newburger (PI), Peter Laussen, Pedro del Nido, Roger Breitbart, Jami Levine, Ellen McGrath, Carolyn Dunbar-Masterson, John E. Mayer, Jr, Frank Pigula, Emile A. Bacha, Francis Fynn-Thompson; Children's Hospital of New York, Wyman Lai (PI), Beth Printz,* Daphne Hsu,* William Hellenbrand, Ismee Williams, Ashwin Prakash,* Seema Mital,* Ralph Mosca,* Darlene Servedio,* Rozelle Corda, Rosalind Korsin, Mary Nash*; Children's Hospital of Philadelphia, Victoria L. Vetter (PI), Sarah Tabbutt,* J. William Gaynor (Study Co-Chair), Chitra Ravishankar, Thomas Spray, Meryl Cohen, Marisa Nolan, Stephanie Piacentino, Sandra DiLullo,* Nicole Mirarchi; Cincinnati Children's Medical Center, D. Woodrow Benson (PI), Catherine Dent Krawczeski, Lois Bogenschutz, Teresa Barnard, Michelle Hamstra, Rachel Griffiths, Kathryn Hogan, Steven Schwartz,* David Nelson, Pirooz Eghtesady*; North Carolina Consortium, Duke University, East Carolina University, Wake Forest University, Page A. W. Anderson (PI), $\dagger$, Jennifer Li (PI), Wesley Covitz, Kari Crawford,* Michael Hines, James Jaggers,* Theodore Koutlas, Charlie Sang, Jr, Lori Jo Sutton, Mingfen Xu; Medical University of South Carolina, J. Philip Saul (PI), Andrew Atz, Girish Shirali, Scott Bradley, Eric Graham, Teresa Atz, Patricia Infinger; Primary Children's Medical Center and the University of Utah, L. LuAnn Minich (PI), John A. Hawkins, $†$ Michael Puchalski, Richard V. Williams, Peter C. Kouretas, Linda M. Lambert, Marian E. Shearrow, Jun A. Porter*; Hospital for Sick Children, Toronto, Brian McCrindle (PI), Joel Kirsh, Chris Caldarone, Elizabeth Radojewski, Svetlana Khaikin, Susan McIntyre, Nancy Slater; University of Michigan, Caren S. Goldberg (PI), Richard G. Ohye (Study Chair), Cheryl Nowak*; Children's Hospital of Wisconsin and Medical College of Wisconsin, Nancy S. Ghanayem (PI), James S. Tweddell, Kathleen A. Mussatto, Michele A. Frommelt, Peter C. Frommelt, Lisa Young-Borkowski.

Auxiliary sites

Children's Hospital Los Angeles, Alan Lewis (PI), Vaughn Starnes, Nancy Pike; The Congenital Heart Institute of Florida (CHIF), Jeffrey P. Jacobs (PI), James A. Quintessenza, Paul J. Chai, David S. Cooper,* J. Blaine John, James C. Huhta, Tina Merola, Tracey Griffith; Emory University, William Mahle (PI), Kirk Kanter, Joel Bond,* Jeryl Huckaby; Nemours Cardiac Center, Christian Pizarro (PI), Carol Prospero; Julie Simons, Gina Baffa, Wolfgang A. Radtke; University of Texas Southwestern Medical Center, Ilana Zeltzer (PI), Tia Tortoriello,* Deborah McElroy, Deborah Town.

Angiography core laboratory

Duke University, John Rhodes, J. Curt Fudge.

\section{APPENDIX. Continued}

Echocardiography core laboratories

Children's Hospital of Wisconsin, Peter Frommelt; Children's Hospital Boston, Gerald Marx.

Genetics core laboratory

Children's Hospital of Philadelphia, Catherine Stolle.

Protocol review committee

Michael Artman (Chair), Erle Austin, Timothy Feltes, Julie Johnson,

Thomas Klitzner, Jeffrey Krischer, G. Paul Matherne.

Data and safety monitoring board

John Kugler (Chair), Rae-Ellen Kavey (Executive Secretary), David J. Driscoll, Mark Galantowicz, Sally A. Hunsberger, Thomas J. Knight, Holly Taylor, Catherine L. Webb.

$P I$, Principle investigator. *No longer at the institution listed. †Deceased. 